\title{
Reseñas
}

\section{Derechos sexuales $y$ reproductivos. Teoría, política y espacio público Mónica Petracci}

2011. Buenos Aires. Teseo. Cantidad de páginas: 223. ISBN: 978-987-1354-97-9

Florencia Laura Rovetto

Dra. en Periodismo y Ciencias de la Comunicación (Univ. Autónoma de Barcelona) Investigadora Asistente CONICET

Docente en la Universidad Nacional de Entre Ríos

Integrante del Núcleo Interdisciplinario de Estudios y Extensión de Género de la Facultad de Ciencia Política y RRII (UNR)

E-mail: florencia.rovetto@gmail.com 
En Argentina, el debate actual a favor de la interrupción voluntaria del embarazo y de los derechos sexuales y reproductivos, impulsado por la militancia feministas y otros grupos de activismo social, se conjuga con un importante caudal de literatura actualizada que abreva en distintos campos del saber vinculados a la psicología, el derecho, la medicina y las ciencias sociales. En este contexto, la obra Derechos sexuales y reproductivos. Teoría, política y espacio público de Mónica Petracci, constituye un aporte original para incorporar al debate y a la lucha por la ampliación de los derechos para las mujeres.

El libro se presenta como el resultado de tres años de trabajo en el proyecto de investigación "Opinión pública sobre derechos sexuales y reproductivos en la Argentina 1994-2006: un consenso estable en el espacio globalizado de opinión" ${ }^{1}$, cuyos hallazgos han sido plasmados en una obra que aborda teoría, política y espacio público en el campo de los derechos sexuales y reproductivos.

El texto se divide en una primera parte, titulada "Entramados teóricos y políticos" y una segunda parte, titulada, "Espacio público, opinión pública y medios de comunicación" que contó con los aportes de Mariana Mattioli, Cecilia Straw, Milca Cuberli, Marina Lois y Andrea Palopoli.

Tanto en la investigación precedente como en el libro que reseñamos, las autoras se proponen comprender los procesos sociales y políticos, así como describir los discursos sociales circulantes en el espacio público, con especial atención en la opinión pública y el discurso de la prensa gráfica en torno a cuatro temáticas relacionadas con la reproducción y la sexualidad en Argentina (1994-2010): anticoncepción de emergencia; aborto; fertilización asistida y VIH/sida, que se encuentran en el cruce de conflictos y controversias espacio público/político (no estatal) y mediático.

1 El proyecto recibió subsidio de la Universidad de Buenos Aries en el marco del programa científico UBACyT 2008-2010 (CS025) con radicación en el Instituto de Investigaciones Gino Germani de la Facultad de Ciencias Sociales de la UBA. 
El trabajo plantea la utilización de una perspectiva comunicacional para el análisis del sistema político y del escenario social, observando las condiciones existentes para el ejercicio de los derechos sexuales y reproductivos. Si bien la perspectiva utilizada no se detalla con claridad, con la investigación, las autoras logran reunir y analizar de forma articulada los discursos circulantes en los medios de comunicación y los estados de la opinión pública (a través de sondeos, tomas de posición, expresiones de movimientos sociales) que por lo general han sido analizados de forma independiente (p. 10). Para lograrlo se basan en un diseño que combina metodologías cualitativas y cuantitativas con fuentes primarias y secundarias.

En la primera parte del libro, las autoras desarrollan una importante reflexión teórica sobre la dialéctica relación entre lo privado y lo público, poniendo en tensión concepciones liberales y republicanas que han demarcado ambas esferas de forma separada. Brown parte del supuesto que las demandas de los sectores oprimidos, junto a los cambios culturales, económicos, políticos y tecnológicos "fueron moviendo las fronteras entre lo público y lo privado, redefinieron los conceptos y permitieron aún con restricciones, que la sexualidad y las sexualidades comenzaran a ser un objeto de debate público y político en América Latina” (p. 16).

Valiéndose de aportes provenientes de la filosofía política como los de Arendt (2005) y Bobbio (2004), la autora se pregunta por el poder y por quiénes pueden o no ser sujetos de derecho sexuales en las sociedades contemporáneas. La autora señala que si bien la cuestión de la sexualidad y la procreación -derechos (no) reproductivos y sexuales- ${ }^{2}$ es "aquello que opera como bisagra entre los dos espacios" (pp. 2223), las fronteras entre lo público y lo privado fueron redefiniéndose socio históricamente, permitiendo (aun con restricciones) que las sexualidades comiencen a ser objeto de debate público y político en la región.

2 Tal como se explica en la introducción del libro, Brown desarrolla la terminología que alude a los derechos sexuales, reproductivos y no reproductivos para sintetizar en una noción amplia todos los eventos relativos a un embarazo y parto seguros y también la anticoncepción y el aborto. 
Asimismo, Brown abunda en la reflexión sobre la participación de las mujeres en la esfera pública en términos discursivos (Habermas, 1986) en donde las demandas personales son debatidas en su dimensión política. Retomando las críticas feministas y marxistas de Fraser (1997) a la concepción habermasiana de esfera pública pone de relieve la necesidad de atender a las desigualdades sociales y la pluralidad de espacios públicos en el que los grupos oprimidos y los contrapúblicos participen de la deliberación en términos equitativos. Finalmente, explora alternativas a partir de la propuesta de Benhabib (2006) y las observaciones de Arendt (2003) sobre la política y la tríada cuerpo-sexoreproducción, proponiendo que los sujetos históricamente excluidos sean considerados asuntos legítimos de demanda en el espacio público político.

Este recorrido teórico se completa con la sistematización analítica de hechos contemporáneos vinculados a la acción política, la jurisprudencia y la formulación de políticas públicas que se desarrollaron en el país sobre derechos sexuales, reproductivos y no reproductivos en las últimas décadas. Para ello, Petracci reúne y da visibilidad a la profusa bibliografía sobre las temáticas producida en el país desde 1983 y pone de manifiesto la viabilidad que estos debates obtuvieron en el marco de la continuidad democrática.

La segunda parte del libro, "Espacio público: opinión pública y medios de comunicación", analiza la agenda de la opinión pública y la construcción discursiva en los medios de comunicación de los cuatro temas abordados en esta obra: aborto, anticoncepción de emergencia, fertilización asistida y VIH/sida. En un primer artículo, Petracci pone de relieve el estado de la opinión pública a través de datos secundarios que señalan grados de acuerdo/desacuerdo; asimismo, analiza datos primarios, incorporando la conformación del nivel de importancia temático asignado al conjunto y a cada uno de los temas mencionados en nueve estudios transversales realizados en el país desde inicios de la década del 90 hasta 2006.

La fortaleza de estos capítulos se encuentra en la sistematización de datos empíricos derivados de los sondeos y su análisis comparativo con resultados hallados en estudios similares producidos en España y 
otros países de Latinoamérica. Como una falencia se destaca que las fuentes utilizadas para dar cuenta del estado de la opinión pública a nivel nacional se centran, en su gran mayoría, en la población de la ciudad de Buenos Aires. Sin embargo, tal déficit no es reprochable a las autoras de la obra sino, más bien, a la disponibilidad de datos ofrecidos por los organismos públicos competentes ${ }^{3}$.

Para completar el análisis empírico, Mariana Matioli, Cecilia Straw y Mónica Petracci abordan, desde una perspectiva cualitativa, la agenda pública de derechos sexuales y reproductivos de las mujeres a través del análisis de las discusiones mantenidas en grupos focales realizados en la Ciudad de Buenos Aires. Los resultados de esta indagación ponen de manifiesto que para las mujeres consultadas los derechos sexuales y reproductivos están presentes en su agenda y que sus opiniones se basan en valores no modificados por el debate en grupo.

Finalmente, Cuberli, Lois y Palopoli basándose, fundamentalmente, en categorías teóricas de Laclau y Mouffe (1987), Žižek (1992; 1993) y Pêcheux (1978) analizan noticias que contienen información sobre los cuatro temas del campo de la salud y los derechos sexuales y reproductivos, publicadas en la prensa gráfica de tirada nacional durante el periodo estudiado ${ }^{4}$. Las autoras parten del supuesto que los discursos sociales, en tanto prácticas significantes que circulan en los medios, permiten conocer los sentidos construidos socialmente y la articulación entre las agendas de los medios, de la opinión pública y del gobierno (p. 133).

En una primera lectura, las estrategias metodológicas y los criterios de selección de los corpus analizados hacen tambalear la coherencia del conjunto de la obra. Pero al releer estos apartados de forma pausada se aprecian puntos de conexión analítica y es ahí donde radica la principal fortaleza del libro. Ciertamente, el texto logra sistematizar diversos análisis empíricos, produciendo una mirada global en la que

3 El repertorio de estudios transversales utilizados en este capítulo se encuentra disponible en un anexo que contiene la descripción de los indicadores y las fuentes consultadas (ver pp. 84-95).

4 El análisis se realizó sobre noticias publicadas en los diarios Clarín, La Nación y Página/12. Las noticias seleccionadas para el análisis corresponden a los periodos 1998, 2002, 2004 y 2008 por ser, según explican las autoras, años representativos de diferentes períodos históricos del país (p. 143). 
las disputas políticas, la movilidad colectiva, la opinión pública, las representaciones sociales y la percepción subjetiva sobre los derechos sexuales y reproductivos se articulan y cobran sentido (p. 99).

\section{Referencias bibliográficas}

ARENDT, H. Conferencias sobre la filosofía política de Kant. Buenos Aires, Paidós, 2003.

ARENDT, H. La condición humana. Buenos Aires, Paidós, 2005.

BENHABIB, S. El ser y el Otro en la ética contemporánea - feminismo, comunitarismo y posmodernismo. Barcelona, Gedisa ediciones, 2006.

BOBBIO, N. Estado, gobierno y sociedad (Por una teoría general de la política). México, Fondo de Cultura Económica, 2004.

FRASER, N. Justice Interruptus. Critical reflections on the "postsocialist" condition. London, Routeledge, 1997.

HABERMAS, J. Historia y crítica de la Opinión Pública. México, GG Mas Media Ediciones, 1986.

LACLAU, E. y MOUFFE, C. Hegemonía y estrategia socialista. Hacia una radicalización de la democracia. México, Siglo XXI, 1987.

PÊCHEUX, M. Hacia un análisis automático del discurso. Madrid, Gredos, 1978.

ŽIŽEK, S. El sublime objeto de la ideología. México, Siglo XXI, 1992.

ŽIŽEK, S. "Más allá del discurso", primera parte, en: LACLAU, E. Nuevas reflexiones sobre la revolución en nuestro tiempo. Buenos Aires, Nueva Visión, 1993.

Fecha de recepción: 21 de febrero de 2013

Fecha de aceptación: 2 de julio de 2013 


\section{Manual de publicación}

1. La revista Cátedra Paralela recibe los siguientes tipos de artículos: relatos de experiencias profesionales, investigaciones, recuperación de tesinas, ensayos, notas y/o reseñas bibliográficas. Los mismos deberán ser preferentemente inéditos.

2. Los artículos publicados no necesariamente representan la opinión del Consejo de Redacción de Cátedra Paralela. Se enviará copia digital del trabajo en Word, con formato RTF, a catedraparalela@ fcpolit.unr.edu.ar, constando en el asunto el título del escrito. Dicha copia se presentará sin los datos del o los/as autores/as y se anexará una hoja que incluirá los datos personales:

- nombre y apellido

- dirección postal

- teléfono

- e-mail

- título (grado y/o posgrado)

- filiación institucional

3. Los Artículos deberán ocupar entre 15 y 20 páginas a espacio interlineado 1.5, incluidas las referencias bibliográficas, en hoja A4. El tipo de letra deberá ser “Times New Roman”, tamaño 12. Asimismo, los artículos deberán ser acompañados de un Resumen, de no más de 200 palabras (aproximadamente 1.000 caracteres) y 4 palabras claves como máximo. Tanto el resumen como las palabras claves deberán figurar en español e inglés.

4. Las Reseñas bibliográficas deberán ocupar un máximo de 3 páginas.

5. Los Relatos de Experiencias Profesionales deberán ocupar un máximo de 8 páginas y constarán de una introducción con los objetivos de la experiencia, descripción del referente empírico, fun- 
damentos teórico-conceptuales, aspectos operativos y un cierre con reflexiones, conclusiones o recomendaciones preliminares de la experiencia. Bibliografía y citas de acuerdo a las normas generales.

6. Las Tesinas recomendadas por el tribunal examinador serán publicadas en parte, es decir, el/la autor/ra seleccionará el aspecto que considere pertinente publicar. Se recomienda seguir el formato tipo artículo y con un máximo de 20 páginas, incluida la bibliografía.

7. En Notas se exponen los comentarios, opiniones y reflexiones preliminares sobre un acontecimiento o hecho de lo cotidiano profesional que inspire a pensar-reflexionar. Deberán ocupar un máximo de 8 páginas.

8. Al pie de página se incluirán, enumeradas automáticamente por el procesador de textos, los siguientes tipos de notas: explicativas (que amplíen algún aspecto mencionado en el texto); aquellas que hagan referencia a otra parte de la misma obra; de agradecimiento.

9. Las referencias de una cita textual o parafraseo de un/a autor/a se realizarán en el texto con el sistema autor-año, por ejemplo: (Cándido, 1964:41), donde se le indica al lector el apellido del/a autor/a que se cita o parafrasea y el año de la obra, además del número de página de donde se extrajo la cita o la idea.

10. Los cuadros, gráficos y mapas se incluirán en hojas separadas del texto, numeradas y tituladas, con la referencia de su ubicación en el texto. Las imágenes de gráficos o cuadros deben entregarse en archivos independientes TIFF o JPG a 300 dpi y ser dibujadas considerando que no se utilizarán colores ni grises para la impresión.

11. La bibliografía se incluirá al final del trabajo, ordenándola alfabéticamente por autor/a y colocando los datos en el orden que se indica a continuación, sin omitir autores/as ni traducir títulos: 


\section{a. Libros:}

APELLIDO, Nombre (del/a autor/a del libro). Título del libro. Lugar, Editorial, año.

b. Artículos o Capítulos de Libros:

APELLIDO, Nombre (del/a autor/a del artículo o capítulo). “Título del artículo o capítulo", en: APELLIDO, Nombre (del/a autor/a, compilador/a, organizador/a o editor/a del libro). Título del libro o revista. Lugar, Editorial, año. Páginas (del artículo o capítulo).

\section{c. Artículos de Publicación Periódica:}

APELLIDO, Nombre (del/a autor/a del artículo o capítulo). “Título del artículo o capítulo", en: Título de la Publicación. Año, Volumen, Número, $\mathrm{N}^{\circ}$ 37. Páginas (del artículo).

\section{d. Fuentes y/o documentos electrónicos:}

APELLIDO, Nombre (del/a autor/a del libro, artículo, ponencia, etc.). Título. Tipo de soporte (CD-ROM; página web; blog). Fecha de publicación. ISBN o ISSN [en línea: fecha de consulta]. Disponible en: link completo.

\section{Sistema de Arbitraje}

Para la aprobación de su publicación, los trabajos serán sometidos a la consideración del Consejo de Redacción y de evaluadores/as externos/as. Se tendrá en cuenta para su aprobación la pertinencia del tema propuesto, la calidad de la publicación, la actualización de la bibliografía y el cumplimiento de normas formales de redacción. En primer lugar, los artículos serán objeto de una evaluación preliminar por parte del Consejo de Redacción, quien determinará la pertinencia para su publicación. Una vez establecido que el artículo cumple tanto con los requisitos temáticos como formales, será enviado a dos pares académicos externos, quienes determinarán, de manera anónima: a) recomendar la publicación sin modificaciones; b) publicar con sugerencias de re-elaboración; c) no recomendar la publicación. Los resultados del proceso de evaluación serán inapelables en todos los 
casos. En caso de ser publicado el artículo, el/los autor/es transfieren todos los derechos de autor a Cátedra Paralela, sin cuyo permiso expreso no podrá reproducirse ninguno de los materiales allí publicados. Asimismo, Cátedra Paralela asume los derechos para editar, publicar, reproducir, distribuir copias, preparar trabajos derivados en papel y/o electrónicos e incluir el artículo en índices nacionales e internacionales o bases de datos. Se solicita a los/as colaboradores/as la entrega de la nota expresa de originalidad y cesión de los derechos de autor/a. La Revista Cátedra Paralela no se hace responsable por los trabajos no publicados ni se obliga a mantener correspondencia con los/as autores/as.

\section{Modelo Nota de Autorización - Revista Cátedra Paralela}

Por la presente autorizo a la Revista Cátedra Paralela, a la publicación del artículo de mi autoría

.........en el $\mathrm{N}^{\circ}$....... del año ......, publicación de la Escuela de Trabajo Social de la UNR y el Colegio de profesionales de Trabajo Social de la $2^{a}$ Circunscripción de la Provincia de Santa Fe.

Se deja constancia de que no corresponde retribución pecuniaria derivada del derecho de autor.

LUGAR Y FECHA:

FIRMA Y ACLARACIÓN: 